\title{
neofilolog
}

\author{
Czasopismo Polskiego Towarzystwa Neofilologicznego \\ ISSN 1429-2173, 2019, NR 52/1, 119-137 \\ http://dx.doi.org/10.14746/n.2019.52.1.10 \\ http://poltowneo.org/
}

\author{
Aleksandra Wach \\ Adam Mickiewicz University in Poznań \\ https://orcid.org/0000-0003-3341-6347 \\ waleks@wa.amu.edu.pl
}

\section{THE AFFECTIVE SIDE OF WRITING MA THESES IN APPLIED LINGUISTICS}

\begin{abstract}
Academic writing, which necessitates a coordination of multiple higherlevel cognitive skills, poses a challenge to graduate students. The heightened cognitive demands often cause negative emotions, such as stress, frustration, discouragement, but can also evoke positive ones, such as pride, satisfaction, and a feeling of accomplishment. This article reports the findings of a longitudinal qualitative study which aimed at exploring the emotions experienced by the participants, eleven students in an MA seminar, in the process of working on their theses, and the affective strategies they used. The data were collected through diaries kept by the participants over one academic year in which they recorded the emotions that accompanied them during the writing task. The data revealed a fluctuating and dynamic nature of the negative and positive emotions, out of which frustration and satisfaction were the most frequently experienced by the participants. Moreover, a range of affective strategies to control emotions and persist in writing were identified in the diary excerpts. The study illuminates the need to cater to the emotional side of graduate students' thesis writing by providing them with support and appropriate training in self-regulation.
\end{abstract}

Keywords: academic writing, MA theses, affective factors, writing anxiety, emotions, affective strategies

Słowa kluczowe: pisanie akademickie, prace magisterskie, czynniki afektywne, lęk związany z pisaniem, emocje, strategie afektywne 


\section{Introduction}

The affective domain, which is related to emotions, feelings and moods, has been recognized as a relevant part of foreign language (L2) learning since 1970s, when humanistic psychology started to exert an influence on L2 education. Since then, $L 2$ research has addressed affect as part of cognition, focusing especially on selected factors, such as anxiety and motivation (Arnold, Brown, 1999). Recent interest in positive psychology in the field of L2 learning and teaching has resulted in a reconsideration of the roles of both negative and positive emotions in the development of various skills and abilities (Dewaele, Maclntyre, 2014; Maclntyre, Mercer, 2014; Siek-Piskozub, 2016). Emotions have also been investigated as a major factor influencing the process of $L 2$ writing, especially academic writing, given the complex multidimensional nature of this activity and the cognitive load it involves (Bazrafkan et al., 2016; Borg, 2001; Daly, 1978; Huerta et al., 2017; Russell-Pinson, Harris, 2017). Academic writing, a crucial skill underlying academic success, necessitates a number of processes, each of which requires substantial levels of concentration and higher-order cognitive skills (Bailey, 2011; Hammann, 2005; Torrance, Galbraith, 2006; Zabihi, 2018). As a consequence, academic writers are likely to experience considerable levels of anxiety, leading to stress, frustration and discouragement. Their task, therefore, requires the use of affective strategies to alleviate stress levels and regulate emotions. Research findings indicate that academic writers are influenced by strong pressures that evoke negative emotions (Bazrafkan et al. 2016; Borg, 2001; Mu, Carrington, 2007); however, research on emotions in academic writing and ways of coping with them has been scant so far.

The present study attempts to add to the existing research by exploring the emotions experienced by a group of students working on their MA papers, and the affective strategies they used to control their emotions and maintain the writing process. First, however, a review of the literature on the demands of academic writing and on the role of affect in the writing process will be presented.

\section{The demands of academic writing in a foreign language}

Writing, one of the four language skills making up language users' communicative competence, is considered to necessitate an array of cognitive and linguistic processes. Scardamalia (1981: 81) lists the following elements that need to be considered in any writing act: "spelling, punctuation, word choice, syntax, textual connections, purpose, organization, clarity, rhythm, euphony, and reader characteristics", all of which place considerable demands on writers. Torrance and Galbraith (2006) add that the interconnection of various processes in 
a writing task causes a considerable cognitive load and puts severe demands on writers' processing capacities. Discussing these processing constraints, they point to two broad strands of research explaining them: 'dual task interference,' in which a focus on more than one cognitive task leads to lowered performance on at least one of them, and 'transient memory,' resulting in problems with efficient association of various types of information due to short-memory limitations.

The writing skill is a basic language skill in academic settings regardless of the field of study, as university students need to take written tests, submit written assignments, and write diploma papers which are a common graduation requirement (Bailey, 2011; Huerta et al., 2017). Coffin et al. (2003) list the following purposes of writing in higher education: assessment, developing students' critical thinking and understanding, an enhancement of their learning opportunities beyond lectures, and training students in skills useful in their future professions. Therefore, as noted by Hammann (2005), an ability to express ideas coherently in writing is an important pre-requisite of academic success. The activities that are essential in university courses as well as in future professional contexts usually require an execution of a specific kind of writing, involving academic writing skills.

Among the different kinds of writing genres, academic writing constitutes a particularly complex cognitive task that usually poses a significant challenge to writers. Bailey (2011) explains that academic writing involves several overlapping steps, such as conducting a library search, selecting appropriate sources, background reading around a topic, taking notes, planning and outlining, as well as writing proper with the use of academic style, and, finally, proofreading and editing. Students need to learn academic lexical registers, the required specific conventions, and referencing formats. They also need to display critical thinking skills, coherence in formulating logical discourse, and time management techniques. A significant demand is connected with processing excessive amounts of information, at the same time constantly organizing and reorganizing it, which contributes to an increased cognitive load of the activity. Moreover, conducting an empirical research project is a frequent requirement in many courses requiring academic writing, such as theses and dissertations. The writing-up of the research organization and findings also requires specific knowledge and skills. Typically, such a report includes a specification of the aims of a study, its methodology, research procedures, an account of the findings, and their critical evaluation (Bitchener, 2010; Coffin et al., 2003).

Zabihi (2018) stresses that while the process of producing an academic text is always cognitively challenging, the demands rise significantly in the case of writing in a foreign language (L2). On top of the tasks of processing large amounts of information, analyzing and reorganizing it, L2 writers need 
to constantly reformulate it in lexical and grammatical chunks which are not necessarily automatically retrieved from their memories. This requires particularly high levels of cognitive effort and conscious attention throughout the task.

\section{Affect in $L 2$ academic writing}

The affective domain, which is connected with the emotional side of performing a task, constitutes another source of factors influencing the process of academic writing. Because of the multiplicity of cognitive demands involved in academic writing, with conducting and reporting research often being part of the tasks, as well as time constraints and social pressures that are often experienced by writers in academic contexts, this kind of writing is particularly prone to evoke strong emotions (Borg, 2001). Maclntyre and Vincze (2017) state that different kinds of emotions can have either positive or negative effects on learning tasks, and Borg (2001) explains how emotions influence the various stages and processes of planning and conducting research. According to Huerta et al. (2017: 716), "writing is one known barrier for individuals aspiring to a master's or a doctoral degree", and hence the proportion of students who drop out during their graduate courses and do not obtain diplomas is increased partly because of the requirement of writing a thesis.

The published literature on the topic of emotions in academic writing focuses on negative emotions, especially writing anxiety (also referred to as writing apprehension). McLeod (1987: 427) defines writing anxiety as "negative, anxious feelings (about oneself as a writer, one's writing situation, or one's writing task) that disrupt some part of the writing process". It can be inferred from this rather broad definition that writing anxiety encompasses a number of specific negative emotions and feelings, such as anger, embarrassment, guilt, etc., that make writers anxious. Writing anxiety has been shown to inhibit academic writers' capacities and their chances of success. Its higher levels are associated with lower performance, as it was found to be negatively correlated with a mastery of mechanical aspects of writing, linguistic accuracy, and the overall communicative efficiency in L1 writing (e.g., Daly, 1978; Oxford, 2016). Zabihi (2018) notes that both the prevalence of writing apprehension and its debilitating effects can reach even higher levels in $\mathrm{L} 2$ academic writers because of the particularly high cognitive demands they need to deal with. In her study, strong negative correlations were revealed between anxiety and the complexity, accuracy, and fluency of $L 2$ students' writing. Oxford (2016) discusses the feelings of fear, guilt resulting from procrastination, worry resulting from approaching deadlines, and negative comparisons with more successful colleagues as accompanying high levels of writing anxiety in an L2 student who is supposed to write a term paper. 
Anxiety is closely connected to another affective factor often associated with academic writing, namely self-efficacy, which is defined as the beliefs held by writers about their own capacities to successfully complete the writing task (Ganguly, Kulkarni, Gupta, 2017; Zabihi, 2018). By exerting an influence on anxiety, self-efficacy is often discussed as indirectly impacting writers' performance, because greater beliefs in one's capabilities usually result in a more willing participation in a task, harder work, longer persistence, and higher achievement as compared with lower levels of self-efficacy (Schunk, 2003; Zabihi, 2018). According to Cheng, Horwitz and Schaller (1999), writing apprehension is often connected with low self-esteem, a dislike of writing, and a fear of being evaluated by others. Russell-Pinson and Harris (2017) discuss other, related concepts leading to procrastination and decreased achievement in $L 2$ dissertation writers. One of them is 'perfectionism,' characterized by self-criticism due to setting very high, often unrealistic, standards. Another one is 'competing priorities', that is, an inability to reconcile writing with other duties, as a result of which one has a feeling of failure; still another one is connected with 'poor time and project management skills'.

The recent emergence of interest in positive psychology in SLA has shifted researchers' attention to include also positive emotions in investigating various aspects of SLA (Dewaele, Maclntyre, 2014; Maclntyre, Mercer, 2014; Siek-Piskozub, 2016). Dewaele and Maclntyre (2014) discuss the broadly defined feeling of enjoyment in learning, which can result, among others, from task completion, concentration on a task, having clear goals and progressing toward them, establishing positive social relations, and receiving helpful feedback. Maclntyre and Vincze (2017) researched the following positive emotions influencing L2 learning: joy, gratitude, serenity, interest, hope, pride, amusement, inspiration, awe, and love. Oxford (2016) notes that anxiety, being a complex and multifaceted emotion, can also lead to feelings of enjoyment, excitement and stimulation in L2 learning situations. Tolerance of anxiety is, however, an individual trait, and not all learners can experience 'positive anxiety'. While little has been written about academic writers' positive emotions, Cayley (2013) states that the topic of writing needs not be dominated by negativity, and the enjoyment of writing should be discussed as well, because "the pleasures of the writing process and its challenges are two sides to the same coin". Oxford (2016) notes that the process of working on a demanding L2 academic writing assignment can stimulate emotions such as energy, optimism, and a general 'positivity'.

The psychological tension that writers experience can be regulated by the use of affective strategies. In the context of $L 2$ learning, affective strategies are defined as 'emotion-regulating' ones (Oxford, 2016: 159). Oxford (1990: 141) divides affective strategies into three main groups according to 
the function they perform: 1) lowering your anxiety (e.g. through using relaxation techniques, music, and laughter), 2) encouraging yourself (through motivational techniques such as positive self-talk and rewarding oneself), and 3) taking your emotional temperature (e.g., observing one's body reactions, seeking emotional support, and keeping a diary). Undergraduate and graduate students, irrespective of their particular field of study, can use very broad repertoires of such strategies in an attempt to overcome negative emotions evoked by the writing process. For example, Bazrafkan et al. (2016) identified four main categories of coping with stress, anxiety and exhaustion by their study participants, medical sciences students who worked on their PhD theses. These categories were: efficient communication with others (colleagues, friends, family members), engaging in various activities, such as physical activity, meditation, listening to music, watching movies, etc., gathering excessive information about the problem encountered in the writing, and, finally, looking for the motivation to finalize the thesis. Mu and Carrington's (2007) participants reported using the following affective strategies in writing their dissertations: rewarding oneself with some days off after a period of intensive writing, reading books not connected with the topic, talking to peers about their writing, setting goals connected with their future careers, and seeking positive feedback from supervisors and other specialists in their fields. Additionally, as noted by Borg (2001), keeping a reflective journal by researchers can be considered to be yet another strategy whose function is, among others, to reduce anxiety resulting from approaching deadlines and other constraints of doing research. The journal writing helped him understand his emotions and the reasons for his behavior, leading to overcoming the problems. Oxford (2016) illustrates the mutual interrelations of affective, cognitive and metacognitive strategies in an L2 academic writing task. Negative emotions can cause strategic behavior in a learner in order to regulate emotions and tap into enhanced cognition, for example, rationalization and problem identification. Aided cognition, in turn, regulates emotions, evokes positive feelings and provides affective support in successful task performance.

\section{The study}

\subsection{The aims of the study}

The present study aimed to explore the emotions experienced by graduate students in the process of writing their MA theses in applied linguistics. Another aim was to investigate the affective strategies applied by the participants to regulate their emotions and proceed with their writing. 


\subsection{Participants}

The participants of the study were 11 second-year students majoring in English in a two-year master's program at the faculty of English at a big Polish university. They attended an MA seminar devoted to learning and teaching English as a foreign language (the researcher was the supervisor), and were in the process of working on their MA papers. There were ten women and one man among the participants, and their age was between 24 and 25. Nine of the participants had graduated from a bachelor's program at the same faculty, and two had finished BA studies in other faculties at the same university. To ensure participants' anonymity and the confidentiality of the data, the participants will be referred to as Student 1, Student 2, etc.

\subsection{Data collection and analysis}

Diaries documenting the process of writing MA theses kept by the participants were the data elicitation tool used in this exploratory study. As noted by Dörnyei (2007), the primary strength of diary studies is that they allow researchers to get access to participants' perspectives in their daily experience, their emotions and moods. Moreover, the evolutionary character of the data can be captured in such studies. The participants kept their diaries for almost nine months, from October 2017 to June 2018. At the beginning of the academic year, they received blank notebooks with oral instructions to make entries on documenting their writing with a special focus on the emotions they would experience. Moreover, information on a voluntary character of participation, and on the researcher's intention to use the data for research and publication purposes was provided. All students from the seminar decided to keep the diaries and hence participate in the research. Although they had a choice concerning the language of the diaries, all participants with an exception of one, who mixed languages, decided to keep them in Polish. ${ }^{1}$ Altogether, 207 pages of handwritten notes were collected. The qualitative data underwent a datadriven content analysis (Creswell, 2014), as a result of which the following general categories were identified: negative emotions, positive emotions, and affective strategies. The data within each category were further hand-coded, and several codes denoting specific emotions and strategies emerged within each category. These were quantified to calculate frequencies, and the most representative excerpts were selected for illustration purposes.

\footnotetext{
${ }^{1}$ Therefore, the quotes provided in the following section (4.4.) have been translated into English by the researcher for the purpose of the present article.
} 


\subsection{The findings of the study}

\subsubsection{Emotions expressed by the participants}

The frequencies of the occurrence of particular emotions as well their illustrations with selected excerpts from the diaries (in the English translations) will be presented in the present section.

\section{- Frequencies of quotes denoting particular emotions}

Table 1 presents the numbers of quotes related to particular specific emotions, together with the number of participants in whose diaries these quotes were identified ${ }^{2}$.

\begin{tabular}{|l|r|r|l|r|r|}
\hline \multicolumn{2}{|c|}{ Negative emotions } & & \multicolumn{2}{r|}{ Positive emotions } \\
\hline Emotion & $\begin{array}{r}\text { No of } \\
\text { quotes }\end{array}$ & $\begin{array}{r}\text { No of } \\
\text { participants }\end{array}$ & Emotion & $\begin{array}{r}\text { No of } \\
\text { quotes }\end{array}$ & $\begin{array}{r}\text { No of } \\
\text { participants }\end{array}$ \\
\hline frustration & 53 & 11 & satisfaction & 42 & 11 \\
feeling overwhelmed & 25 & 10 & a feeling of accomplishment & 27 & 9 \\
stress & 25 & 9 & hope & 23 & 9 \\
discouragement & 21 & 8 & enjoyment & 19 & 8 \\
doubt & 7 & pride & 17 & 6 \\
tiredness & 17 & 9 & enthusiasm & 14 \\
fear & 17 & 6 & relief & 9 \\
low self-efficacy & 16 & 15 & & & 9 \\
guilt & 14 & 6 & 5 & & \\
anger & 7 & 6 & & \\
worry & & 5 & & \\
\hline
\end{tabular}

Table 1: The total numbers of quotes denoting negative and positive emotions, and of participants who included them in their diaries.

As can be seen in Table 1, eleven negative and seven positive types of emotions emerged in the analysis of the diaries. Altogether, negative emotions were expressed in 218 quotes, and positive emotions in 162 quotes. Frustration was the most prevalent emotion, followed by a feeling of satisfaction. A feeling of accomplishment, stress, and feeling overwhelmed were also particularly frequently reported emotions.

\footnotetext{
${ }^{2}$ The number of participants seems to be important, because the same emotion was often expressed by a single participant in numerous quotes. Therefore, the higher the number of participants in Table 1, the more widely a give emotion was represented in the sample.
} 


\section{- Illustrations of negative emotions}

Different causes of frustration were reported. A frequent one was connected with the time factor, specifically, not having enough time to concentrate on writing and one's inefficient time management. For example, Student 3 wrote, "Weeks pass way too fast. I have to submit the chapter in less than a month, and I've been doing really badly. Recently l've been able to write no more than a page a day." Student 8's comment displays frustration with her own incapability to stay concentrated on the task: "I can't focus, I lack words! My writing takes too long, I've been sitting for 4 hours and haven't even written a page! A tragedy!" Competing priorities, connected with urgent class assignments and other obligations that the participants faced, were another source of frustration, as can be seen in the following excerpts: "Frustration goes up and motivation goes down when I realize that this week I can only devote one day to writing" (Student 10) and "I am frustrated by the constant shortage of time and the number of other duties, for example, I have to waste my precious time on washing the dishes" (Student 9). Frustration was also caused by the challenge of finding appropriate source materials, selecting them and using them in one's own writing, as illustrated in the following quote: "I got stuck again. I have nothing to put in Chapter 3. (...) If Google can't find anything, where else can I look for it?" (Student 1). The feedback the participants received on the portions of their writing was another frequently reported source of frustration, especially when the amount of necessary revision was substantial. Student 2 wrote, "In fact, I have to rewrite the whole chapter. I broke down and I thought I wouldn't be able to correct it."

Time-related issues were also the predominant cause of high levels of stress. The looming deadlines for submitting chapters were a particularly strong factor here, present in practically all diaries. This can be seen in the following excerpt: "I really stress out, because I will definitely not make it for the deadline. I don't know when and what to write, I have a block and no inspiration" (Student 2). The seminar classes, in which the students were reminded of the deadlines and expected to submit their work, were a source of stress for some of them. Student 10 noted, "I get really stressed after each seminar", and Student 5 reported having sleep problems because of stress: "Before every Tuesday I get some kind of neurosis, sometimes I don't sleep at all." Planning and conducting research, as well as analyzing the empirical data, were another frequently reported source of stress. Student 5 found interviewing her study participants very stressful ("I think I am more stressed than they are"), and for Student 6, technical problems with processing the data by software was a source of stress.

The time constraints and a multitude of duties also contributed to the participants' feeling of being overwhelmed. Most of the participants complained 
about having too many homework assignments for other courses, which made it impossible to fully focus on writing the MA papers and ensure their higher quality. Student 11 noted, "I am writing. Five hundred things at the same time. All of them will have to improved." Student 3's comment refers to university duties, work obligations, and everyday issues, all of which put high demands on her: "It's 9 p.m., since the morning I've had 5 hours of my teaching practicum and 5 hours of private classes. I can't write anything today. (...) I'm overwhelmed with teaching, plus university courses and preparations for my wedding". The feeling of being overwhelmed also resulted from the volume of work involved in writing the paper, as illustrated by these quotes: "I am overwhelmed by the amount of background reading materials to analyze" (Student 2) and "Today it was like this: the computer was on, the MA paper file displayed. When I saw how many articles I had downloaded, I immediately switched it off" (Student 5).

The sustained strain and the cognitive and management challenges led to a feeling of discouragement experienced by the participants. In the diaries, they often reported lowered moods and motivation to continue working on their papers due to the prolonged activity and recurring difficulties. This is aptly illustrated by the following comments: "Chapter 2 is not revised yet, and I already have to start chapter 3. I feel like crying when I think of the amount of work and stress I've been through" (Student 3), and "Yet another week of working on the paper. I am totally fed up" (Student 9). Student 8 was disheartened enough to question the need to continue working: "It costs me too much. I start wondering whether I really need this MA. No stamina. "A number of diary entries expressed a related feeling, that of tiredness. The students complained about being mentally and physically exhausted after hours of hard work, often connected with a need to take a break. Student 7's comment is quite representative of this: "The second night spent on writing. I'm so tired. I'm going to bed".

The feeling of doubt appeared when the participants were not sure about their choice of content, structuring the papers, applying writing conventions, and data collection and analysis techniques. Another frequent emotion, fear, arose when the students were submitting chapters and expecting negative feedback, and when they suspected they would not manage to meet the deadlines. Guilt was evoked as a result of not working hard enough, being distracted, and procrastinating. Low self-efficacy was evident in statements such as "I don't believe in myself and I always expect to get my work back covered with red-ink corrections" (Student 10) and "I can't do it properly. I think I overestimated my abilities" (Student 3). The participants' anger was directed either at themselves, at the circumstances which prevented them from working, or at the difficulties they encountered (e.g., failing technology, missing sources, etc.). Finally, the students' worries mainly concerned too little time to fulfill the tasks. 


\section{- Illustrations of positive emotions}

Out of the positive emotions, satisfaction was the most frequently expressed one. It was mainly evoked by the participants' hard work, a sense of progressing, and by the feeling that the result of their work was satisfactory, especially when the positive outcomes followed particularly strong effort. For example, Student 2 wrote, "I was in the library for a long time, 5-6 hours, and I feel good, because I managed to scan all the materials I needed", and Student 4 made the following comment: "I am halfway through the work planned for today and I feel great satisfaction already". Student 6 highlighted the good final effects of her work after laborious revisions following a feedback session: "I am really satisfied with the final version of my first chapter. I've tried to implement the changes suggested by the teacher. Now it seems to come together very nicely." For Student 11, comparing her progress to that made by her colleagues was a source of satisfaction. She noted, "I am progressing. It's good to know (...) that the others are behind me in terms of progression". Some of the participants expressed their satisfaction with having managed to grasp the technical aspects of analyzing their research data, as is evidenced in the following quotations: "I have finally come to terms with SPSS, and the results even make sense" (Student 1), and "Great, the calculations are just fine, the Cronbach and the correlations, and the results are interesting" (Student 7).

Satisfaction is very close to the second most frequent emotion experienced by the participants, a feeling of accomplishment. This feeling was evoked when the participants had accomplished something, e.g., submitted a chapter or met a deadline. For example, Student 1 noted, "I don't know how l've accomplished this. At first, I didn't even know what I wanted to write about, and now it has come out really well". Student 2 put down the following exclamation: "After the final revisions I DID IT! The MA paper is ready!", and Student 6 wrote, "Nothing motivates me more than a submitted chapter. Or, rather, there is such a thing: a chapter that is already printed out, after the revisions!"

Pride, a feeling of very strong satisfaction, was also often evoked by a certain achievement, as exemplified by these excerpts: "I am mega proud of having submitted chapter 2, especially that I was one of the first to do it" (Student 5) and "Today my first paragraph was created on the train. I'm so proud!" (Student 9). Pride also resulted from being able to understand something particularly difficult, for example, statistics: "I am proud of making sense of the statistical tests" (Student 7), from effective self-regulation: "I think I can be proud of myself. According to my plan, I work on my paper every day for an hour" (Student 10), and from the effort invested in the work: "I never thought I could work so hard" (Student 7). 
Hope, expressed as optimistic prospects of a smooth writing process and of a positive evaluation by the supervisor, was another frequent emotion revealed in the diary entries. This is illustrated by the following examples: "I keep repeating that since I have managed to do so much so far, I will do fine" (Student 3), "I hope chapter 2 will be less chaotic than the first version of chapter 1" (Student 2), and "Christmas and some free time are approaching, so I hope I'll be able to create something" (Student 1).

A number of the entries pointed to certain levels of enjoyment derived from the process of writing. This was sometimes stimulated by some interesting content encountered in the sources, as, for example, in the quote made by Student 5: "Things got moving. Chapter 3 is much nicer to write, because finally I'm interested in its topic", and by Student 7: "Chapter 1 is going fine, the sources are fun to read." Most participants, however, found reporting on their own studies to be the most enjoyable part of the work: "Wow, writing about what I have done myself is really cool (...) It's so nice to come back to my memories, my interviews. Three days of transcription, but it was quite enjoyable" (Student 6); "It's great that the study actually revealed something. I really feel like writing about it" (Student 11 ). Moreover, it needs to be mentioned that Student 7 found the time pressure enjoyable, noting: "I need this adrenaline to get motivated. Moreover, I like it."

Throughout working on the papers, the participants appeared to feel enthusiastic about the various elements involved in the writing process. Their enthusiasm was evident in their invigoration and enhanced motivation to write, and was caused by a variety of specific factors, such as obtaining new inspiring sources: "I have just found a great book which is user-friendly, nicely edited and has real-life stories in it" (Student 6); "Right after work I sit down to read the articles - I am enthusiastic to do it after my recent fruitful library search" (Student 9). For others, it was stimulated by the prospect of conducting research, as can be seen in Student 11's quote: "Next week I'm starting my study. I am... excited!" Finally, some students noted that the feedback from the supervisor was a source of new energy for them: "After fruitful feedback with my supervisor I've gathered new energy to continue writing and reading" (Student 6).

The final positive emotion, relief, was caused by extending a deadline: "I am relieved because tomorrow's seminar has been cancelled. I have gained another week to complete the chapter" (Student 9). However, it was most commonly experienced after a completion of certain stage, such as a chapter, a literature review, or a whole paper. Student 10 wrote, "I submitted the chapter at last! I can't describe the relief I feel. I want to fly!" 


\subsubsection{Affective strategies applied by the writers}

The diary entries contained numerous examples of affective strategies used by the participants to regulate their emotions throughout the process of writing. Four groups of such strategies were identified. The numbers of the quotations in which they were revealed, and of the participants who reported using them, are presented in Table 2.

\begin{tabular}{|l|r|r|}
\hline Affective strategies & No of quotes & No of participants \\
\hline engaging in other activities & 24 & 9 \\
rewarding oneself & 17 & 7 \\
seeking consolation and help from others & 16 & 5 \\
keeping a diary & 5 & 4 \\
\hline
\end{tabular}

Table 2: Total numbers of quotes referring to the use of affective strategies and of the participants who used them.

Engaging in other activities was a way of taking some time off from working on the papers. The participants resorted to this strategy in order to rest, to regain energy, to get a new perspective on what they wrote about, and, generally, to be able to return to writing with enhanced enthusiasm. They engaged in a variety of activities, some of which are listed in the following quotations from the diaries:

- "I'll listen to music or go out with my boyfriend to refresh my mind, because I'm starting to forget what I'm reading about" (Student 1);

- "I have turned it off and I'm going to do yoga. I need a break" (Student 5);

- "I'm going to listen to some music and close my eyes for a while. Such mental detox will do me good" (Student 8);

- "On Thursday I was transcribing the interview, and on Friday I was cleaning the flat. The cleaning was surprisingly pleasant. I didn't waste the time, simultaneously getting a break from intellectual work" (Student 9).

The strategy of rewarding oneself was used after some effort in order to maintain the motivation to pursue further work. The rewards took different forms, as exemplified by the following quotes:

- "When I write 5 pages, I'll go to the gym" (Student 6);

- "A page has been written. My reward for the job: pizza" (Student 8);

- "I have deserved an episode of a series and some chips" (Student 9);

- "I have definitely deserved a reward - I'm giving myself a week of relaxation with no thinking about the paper, articles, and the like" (Student 10).

Seeking consolation and help from others is a strategy which involves other people, not necessarily those who are directly engaged with the task. 
Some of the participants reported using this strategy quite frequently, skillfully turning to others in order to get psychological support and some kind of help:

- "I share my stress with my boyfriend, and his composure gives me a lot of support and help with controlling my emotions" (Student 1);

- "My fiancé tries to motivate me to write the paper. When I do nothing for a while, he reminds me to start writing" (Student 3);

- "My friend called today. She's also having problems with her BSC paper, so we support each other. It's good to have someone who's not doing very well either" (Student 5);

- "It would be good if someone had a look at my coding. I'll ask my mum" (Student 6).

Finally, the keeping of the diary appeared to be an effective strategy for some of the participants. This was evident in some of the excerpts:

- "I wish I could keep the diary till the end of the writing. It makes me aware of certain issues. I guess I will keep it longer" (Student 3);

- "The diary helps me reflect on my emotions" (Student 4);

- "As I look through my diary, I can see how many negative emotions there are inside me. The diary itself is a way of relieving stress" (Student 5);

- "This notebook helps me organize my writing" (Student 6).

\section{Discussion and implications}

The study findings revealed a number of both negative and positive emotions that were experienced by the participants in the process of working on their MA papers. It could be seen that the quotes which expressed negative emotions outnumbered those which expressed positive ones, and the overall number of negative emotions identified in the diaries was higher than the number of positive ones. However, given the strenuous nature of the task the participants were involved in, the high volume of the positive emotions it generated is worth stressing. The general overtone of the diaries was not dominated by negativity; in fact, both negativity and positivity permeated through the entries. It is worth highlighting that both were reflected in each diary, and there was no diary in which either negative or positive emotions would definitely predominate. This general perception was also evidenced in frustration being the most frequent emotion, and satisfaction the second most frequent one, both experienced by all participants. Another noteworthy observation is that the emotions fluctuated, with negative feelings transforming to positive ones and the other way round, often from one diary entry to the following one, or even within a single entry. Although the shifts in the emotional temperature 
were not always that abrupt, their fluctuations clearly pointed to a dynamic nature of the emotional dimension of engaging in a long-term intellectual activity, of which thesis writing is an example. The findings concerning the coexistence and dynamic interrelations of various emotions seem to confirm Maclntyre and Vincze's (2017: 68) observation that negative and positive emotions, such as, for example, anxiety and enjoyment, are "two interrelated dimensions, each of which with its own trajectory of development over time". They explain that in an L2 situation, when it is natural for a learner to experience both successes and failures, the complementarity of positive and negative emotions is particularly relevant. In the present study, the dynamic and transformational character of the participants' emotions and moods was clearly visible because of the process-oriented, longitudinal and introspective character of the data elicitation method.

Out of the negative emotions, frustration, stress, a feeling of being overwhelmed, discouragement, doubt, and tiredness were the most frequent ones. On the other hand, satisfaction, followed by a feeling of accomplishment, hope, enjoyment, and pride, were the most frequently reported positive emotions. Each of the emotions appeared to involve a complex interplay of specific factors that caused it. Generally, the following factors could be identified as stimulating most emotions: conducting a library search (i.e. having too many or too few sources, or finding good sources), deadlines (connected to pressure and time management issues), an overload of other activities, a cognitive challenge (connected to the difficulty of the tasks involved), competing priorities, progressing, comparisons (with peers and with prior experience), and, finally, feedback from the supervisor. For example, a cognitive challenge could stimulate frustration, stress, feeling overwhelmed, and being scared on the one hand, and a feeling of satisfaction or pride on the other hand, if the challenge was overcome successfully. Moreover, it was also revealed how a generally negative emotion, stress caused by a time pressure, led to a positive feeling of satisfaction in one participant who admitted being stimulated and motivated by such situations. This is in line with what Oxford (2016) calls 'positive anxiety', and provides additional evidence for a complexity of negative and positive emotions.

The diary entries also contained numerous examples of the affective strategies that the participants used in order to cope with negative emotions and to maintain or evoke positive ones ${ }^{3}$. The four types and the specific examples of the strategies generally coincided with Oxford's (1990) typology, in which she distinguished 'lowering anxiety', 'self-encouragement', and 'regulating emotional temperature.' Engaging in other activities, such as listening

\footnotetext{
${ }^{3}$ A number of metacognitive strategies were identified as well, however, they are beyond the scope of the present analysis.
} 
to music, taking a walk, having a snack, in order to take time off from the tiring and intellectually involving task, was the most frequently used type of strategy. Rewarding oneself for bigger or smaller successes was the second most frequently reported strategy, and turning to others for help or consolation, which could be called a socio-affective strategy, was the following one. Interestingly, the strategy choice mirrored that reported by Mu and Carrington (2007) and Bazrafkan et al. (2016), which shows that under similar circumstances, people tend to resort to similar strategies irrespective of the different institutional and cultural contexts. Judging by the diary entries, the affective strategies applied by the participants were effective in alleviating stress and stimulating enthusiasm, and, as a result, in facilitating the writing process. Finally, it seems important to point out that keeping the diaries was acknowledged by the participants to be a useful affective strategy. In this way, the diaries performed a dual role in the present study: as a research tool, and as a strategy which facilitated reflection and understanding their emotions by the participants.

The implications that can be formulated on the basis of the results concern a need to recognize the importance of students' emotions in the process of working on their diploma papers by their supervisors, other faculty staff, peer students, and the students themselves. Unfortunately, it seems that the main focus in supervisor-student collaboration often falls mainly or entirely on the cognitive side of the MA project, with a complete neglect of the student's emotions, feelings, and moods. The way feedback on a student's writing is delivered by the supervisor seems to be a particularly important issue. It is recommended that supervisors provide positive feedback as well, and express an appreciation of a student's effort. Otherwise, feeling overwhelmed, frustrated, and left alone with their negative emotions, students can find efficient work on their papers extremely difficult, and often even impossible. If nothing is done, frustration and a feeling of low efficacy can grow, leading to overt helplessness and failure. Therefore, emotional support is needed in the course of classes and beyond them. It can take the form of regular informal group chats about students' feelings related to writing, which can initiate an informal yet powerful peer support system. It is easier to open up if others face the same problems, as was also revealed in the present study. Getting acquainted with published articles about writing anxiety, especially in the context of theses writing, can also be helpful, especially if they can be further discussed in class. Finally, explicit training in the use of affective strategies can be a good idea. Some of the students can assume that taking time off is a sign of laziness; if they learn that is a purposeful strategy, their self-esteem can be boosted. Keeping a writing diary can also be recommended as a useful emotion-regulating strategy. 


\section{Final conclusions}

The findings of the study revealed a number of emotions that accompanied the participants in the process of writing their MA papers, displaying the complexity and the dynamic nature of these emotions and their interrelations. The study thus provides a confirmation of a significant role of the affective side of being involved in cognitively demanding academic writing activities. The analysis of the results leads to the conclusion that this dimension of a challenging task performance must not be neglected, because it can contribute to a success or failure of an undertaking to the same extent as cognitive factors. Therefore, academic writers need to be given support in managing and regulating their emotions to help them successfully complete their assignments, and at the same time maintain high levels of motivation and a feeling of accomplishment.

I would like to thank the study participants, my MA seminar students, for keeping the diaries and generously sharing them with me.

\section{REFERENCES}

Arnold J., Brown H. D. (1999), A map of the terrain (in) Arnold, J. (ed.), Affect in language learning. Cambridge: Cambridge University Press, pp. 1-24.

Bailey S. (2011), Academic writing. A handbook for international students. Third edition. New York and London: Routledge.

Bazrafkan L., Shokrpour N., Yousefi A., Yamani, N. (2016), Management of stress and anxiety among $P h D$ students during thesis writing: A qualitative study (in) "The Health Care Manager", No 35, pp. 231-240.

Bitchener J. (2010), Writing and applied linguistics thesis or dissertation. Basingstoke: Palgrave Macmillan.

Borg S. (2001), The research journal: a tool for promoting and understanding researcher development (in) "Language Teaching Research", No 5, pp. 156-177.

Cayley R. (2013), Writing and enjoyment (in) "Explorations of style: A blog about academic writing". Online: https://explorationsofstyle.com/2013/04/12/links-writing-and-enjoyment/ [ED: 2.05.2018].

Cheng Y., Horwitz E., Schallert, D. (1999), Language anxiety: Differentiating writing and speaking components (in) "Language Learning", No 49, pp. 417-446.

Coffin C., Curry M., Goodman S., Hewings A., Lillis T., Swann J. (2003), Teaching academic writing. A toolkit for higher education. New York and London: Routledge.

Creswell J. (2014), Research design: Qualitative, quantitative, and mixed methods approaches. $4^{\text {th }}$ edition. Thousand Oaks: SAGE Publications. 
Daly J. (1978), Writing apprehension and writing competency (in) "The Journal of Educational Research", No 72, pp. 10-14.

Dewaele J.-M., MacIntyre P. (2014), The two faces of Janus? Anxiety and enjoyment in the foreign language classroom (in) "Studies in Second Language Learning and Teaching", No 4, pp. 237-274.

Dörnyei Z. (2007), Research methods in applied linguistics: Quantitative, qualitative, and mixed methodologies. Oxford: Oxford University Press.

Hammann L. (2005), Self-regulation in academic writing tasks (in) "International Journal of Teaching and Learning in Higher Education", No 17, pp. 15-26.

Huerta M., Goodson P., Beigi M., Chlup D. (2017), Graduate students as academic writers: writing anxiety, self-efficacy and emotional intelligence (in) "Higher Education Research \& Development", No 36, pp. 716-729.

Ganguly S., Kulkarni M., Gupta M. (2017), Predictors of academic performance among Indian students (in) "Social Psychology of Education", No 20, pp. 139-157.

MacIntyre P., Mercer S. (2014), Introducing positive psychology to SLA (in) "Studies in Second Language Learning and Teaching", No 4, pp. 153-172.

MacIntyre P., Vincze L. (2017), Positive and negative emotions underlie motivation for L2 learning (in) "Second Language Learning and Teaching", No 7, pp. 61-88.

McLeod S. (1987), Some thoughts about feelings: The affective domain and the writing process (in) "College Composition and Communication", No 38, pp. 426-435.

Mu C., Carrington S. (2007), An investigation of three Chinese students' English writing strategies (in) "TESL-EJ", No 11, pp. 1-23.

Oxford R. (1990). Language learning strategies: What every teacher should know. Boston: Heinle \& Heinle Publishers.

Oxford R. (2016), Teaching and researching language learning strategies: Selfregulation in context. $2^{\text {nd }}$ edition. New York and London: Routledge.

Russell-Pinson L., Harris, M. (2017), Anguish and anxiety, stress and strain: Attending to writers' stress in the dissertation process (in) "Journal of Second Language Writing" (Advance access). Online: https://www.sciencedirect.com/ science/article/abs/pii/S1060374317302977 [ED: 2.05.2018].

Scardamalia M. (1981), How children cope with the cognitive demands of writing (in) Frederiksen C., Dominic J. (eds.), Writing: The nature, development, and teaching of written communication. Hillsdale, NJ: Lawrence Erlbaum, pp. 81-103.

Schunk D. (2003), Self-efficacy for reading and writing: Influence of modeling, goal setting, and self-evaluation (in) "Reading \& Writing Quarterly", No 19, pp. 159-172. 
Siek-Piskozub T. (2016), The compatibility of positive psychology and the Ludic strategy in foreign language education (in) "Glottodidactica", NoXLIII, pp. 97-106. Torrance M., Galbraith, D. (2006), The processing demands of writing (in) MacArthur C., Graham S., Fitzgerald J. (eds.), Handbook of Writing Research. New York, NY: Guilford Press, pp. 67-80.

Zabihi R. (2018), The role of cognitive and affective factors in measures of $L 2$ writing (in) "Written Communication", No 35, pp. 32-57. 